\title{
Efek Penggunaan Strategi Konflik Kognitif Terhadap Hasil Belajar Kognitif Siswa
}

\author{
Ni Nyoman Sri Putu Verawati \\ Universitas Mataram, Jl. Majapahit No. 62 Mataram 83125, INDONESIA. \\ Coresponding author: veyra@unram.ac.id
}

\begin{abstract}
Abstrak: Hasil belajar kognitif merupakan aspek penting pembelajaran di semua level pendidikan, sehingga intervensi multimetode pembelajaran diupayakan untuk mencapai hasil belajar kognitif yang lebih baik. Penelitian ini bertujuan mengetahui efek penggunaan strategi konflik kognitif terhadap hasil belajar kognitif siswa. Penelitian ini merupakan penelitian eksperimen menggunakan one group pretest posttest design. Sampel penelitian adalah 35 orang siswa di salah satu sekolah menengah atas di Kota Mataram. Strategi konflik kognitif dikonduksikan dalam penelitian pada materi pokok GLB dan GLBB. Pengukuran hasil belajar kognitif menggunakan instrumen tes dan diberikan kepada siswa sebagai pretest dan posttest. Hasil penelitian menunjukkan bahwa hasil belajar kognitif siswa meningkat setelah pembelajaran menggunakan strategi konflik kognitif (mean: 3.4914) signifikan (p: 0.000). Hasil tersebut juga didukung hasil analisis n-gain hasil belajar kognitif siswa setelah pembelajaran dengan nilai 0.74 dengan kategori tinggi sehingga dinyatakan efektif untuk meningkatkan hasil belajar kognitif siswa.
\end{abstract}

Kata Kunci: Strategi Konflik Kognitif, Hasil Belajar Kognitif

Abstract: Cognitive learning outcomes are an important aspect of learning at all levels of education, so that multimethodal interventions are strived to achieve better cognitive learning outcomes. This study aims to determine the effect of cognitive conflict strategies on student cognitive learning outcomes. This research is an experimental research using one group pretest posttest design. The research sample was 35 students in one high school in the city of Mataram. Cognitive conflict strategies are conditioned in research on the subject matter of GLB and GLBB. Measurement of cognitive learning outcomes using test instruments and given to students as a pretest and posttest. The results showed that students' cognitive learning outcomes improved after learning using cognitive conflict strategies (mean: 3.4914) significantly (p: 0.000). These results are also supported by the results of the n-gain analysis of students' cognitive learning outcomes after learning with a value of 0.74 in the high category so that it is declared effective for improving student cognitive learning outcomes.

Keywords: Cognitive Conflict Strategies, Cognitive Learning Outcomes

\section{PENDAHULUAN}

Hasil belajar merupakan bagian terpenting dalam pembelajaran. Hasil belajar adalah kemampuan-kemampuan yang dimiliki siswa setelah menerima pengalaman belajarnya. Penilaian hasil belajar adalah proses pemberian nilai terhadap hasil belajar yang telah dicapai siswa berdasarkan kriteria tertentu. Hasil belajar dapat dilihat melalui kegiatan evaluasi yang bertujuan untuk mendapatkan data pembuktian yang akan menunjukkan tingkat kemampuan siswa dalam mencapai tujuan pembelajaran. Hasil belajar siswa pada hakikatnya adalah perubahan mencakup bidang kognitif, afektif dan psikomotoris yang berorientasi pada proses belajar mengajar yang dialami siswa (Sudjana, 2010).

Sistem pendidikan nasional dan rumusan tujuan pendidikan; baik tujuan kurikuler maupun tujuan instruksional pada umumnya menggunakan klasifikasi hasil belajar Bloom yang secara garis besar membaginya menjadi tiga ranah, ranah kognitif, afektif, dan psikomotoris. Ranah kognitif berkenaan dengan hasil belajar intelektual yang terdiri dari enam tingkatan, yakni: pengetahuan $(\mathrm{C} 1)$ pemahaman $(\mathrm{C} 2)$, penerapan (C3), analisis (C4), sintesis (C5), dan evaluasi (C6). Untuk penilaian ranah afektif merupakan hasil belajar yang mencakup lima tingkatan yaitu: receiving, 
responding, valueing, organizing, dan characterizing by a value complex. Bobot skor disusun meningkat, dimulai dari tingkat yang paling sederhana hingga yang paling kompleks, instrumen yang digunakan adalah checlist, Krathwohl (1994). Untuk penilaian psikomotor terdiri dari imitation, manipulation, precicion, dan articulation. Skor pada ranah psikomotor juga disusun meningkat sejalan dengan kekompleksan setiap tingkatan dalam ranah tersebut. Instrumen yang digunakan adalah lembar checklist. Secara garis besar hasil belajar dipengaruhi oleh 2 faktor, yaitu faktor internal dan ekternal. Faktor internal misalnya sikap, minat, dan motivasi, serta kemampuan siswa. Sedangkan faktor eksternal, misalnya fasilitas, lingkungan sekolah, dan strategi pembelajaran. Kualitas pembelajaran menjadi faktor penting bagi hasil belajar (Arikunto, 2006)

Pembelajaran sering diidentikkan dengan proses berpikir yang merupakan aktivitas kognitif untuk memperoleh pengetahuan serta menghasilkan representasi mental yang baru. Proses kognitif tidak dapat berkembang secara alamiah, oleh sebab itu harus diperkaya oleh berbagai stimulus dan suasana yang beragam. Salah satu stimulasi yang dapat digunakan dalam pembelajaran, yaitu penggunaan strategi konflik kognitif. Konflik kognitif merupakan suatu kondisi di mana terjadi pertentangan dalam struktur kognitif siswa (Kang et al., 2004). Pertentangan terjadi karena perbedaan konsepsi awal yang dimiliki siswa dengan pengalaman belajar mereka (Hewson, 1988; Stavy \& Berkovitz, 1980). Konflik kognitif terjadi ketika keseimbangan mental siswa terganggu oleh pengalaman (disebut sebagai "data anomali") yang tidak sesuai dengan pemahaman mereka saat ini (Foster, 2011).

Strategi konflik kognitif melibatkan: (a) mengidentifikasi kondisi pengetahuan siswa saat ini; (b) menghadapkan siswa dengan informasi yang bertentangan (kontradiktif); dan (c) mengevaluasi tingkat perubahan konseptual antara ide-ide atau keyakinan awal siswa dengan melakukan posttest setelah intervensi instruksional (Hewson \& Hewson, 1984). Untuk memahami konflik kognitif, pengetahuan tentang model proses konflik kognitif sangat penting, karena menjelaskan tahapan di mana konflik kognitif terjadi dan bagaimana menyelesaikan konflik yang dihasilkan. Proses konflik kognitif terjadi ketika seorang pelajar: (a) mengenali situasi anomali, (b) menyatakan minat atau sebaliknya terkait konflik yang ada, dan (c) terlibat dalam penilaian kembali situasi proses kognitif. Ketika siswa menyadari bahwa suatu situasi yang ada tidak sesuai dengan konsep mereka, mereka menjadi tertarik atau sebaliknya tentang situasi ini (Lee et al., 2003).

Strategi konflik kognitif merupakan strategi pengubahan konsepsi yang memungkinkan dapat menyadarkan siswa atas kekeliruan konsepsinya. Apabila siswa menyadari ketidaksesuaian antara pengetahuan yang telah dimiliki dengan pengalaman yang baru, maka akan terjadi konflik dalam pikirannya (konflik kognitif). Siswa akan meragukan pengetahuan yang telah dimilikinya dan membentuk pengetahuan baru. Hal ini sesuai dengan pandangan Piaget yang mengatakan bahwa bila keseimbangan antara apa yang dipahami dengan apa yang ditemui terganggu, anak memiliki kesempatan untuk berkembang. Apabila skema yang dimiliki seseorang tidak dapat digunakan untuk menghadapi pengalaman baru, maka terjadi keseimbangan antara apa yang dipahami dengan apa yang ditemui. Secara alamiah, manusia selalu berusaha menghilangkan disequilibrium dan menyusun skema baru atau memodifikasi 
skema lama sampai terjadi keseimbangan (Slavin, 1997).

Ernest (1991) menyebutkan bahwa konflik kognitif terjadi ketika terdapat konflik antara dua skemata yaitu terjadinya inkonsistensi atau pertentangan. Inkonsistensi atau pertentangan yang dimaksud adalah adanya pemahaman-pemahaman yang terkait dengan suatu konsep atau informasi yang saling bertentangan, tidak bersesuaian, atau tidak berintegrasi. Sigel (Lee, 2003) menggambarkan tiga jenis konflik kognitif yaitu: (1) konflik kognitif internal, yaitu konflik antara dua ide yang bertentangan dalam struktur kognitif atau konflik antar pemahaman-pemahaman dalam struktur kognitif, (2) konflik sosial eksternal yaitu konflik antara dua kejadian eksternal atau informasi dari luar. Konflik ini dapat dijelaskan pada seseorang yang menyaksikan dua orang berdebat atau membaca suatu informasi yang tidak bersesuaian dari sumber yang berbeda; dan (3) konflik internaleksternal, yaitu konflik antara pemahaman seseorang tentang suatu informasi dalam struktur kognitifnya dengan kejadian luar atau sumber informasi luar. Namun pada dasarnya ketiga jenis konflik kognitif yang dikemukakan oleh Siegel terebut merupakan suatu konflik yang terjadi akibat pemahamanpemahaman terhadap informasi yang diterima atau yang telah tersimpan dalam struktur kognitif seseorang tidak saling berintegrasi menjadi satu pemahaman konsep yang sama.

Kwon \& Lee (2001) mendefinisikan konflik kognitif, yaitu "Cognitive conflict is defined as a conflict between cognitive structure (i.e., an organized knowledge structure in the brain) and environment (i.e. a experiment, demonstration, peer's opinion, book, or something like that), or a conflict between conception in cognitive structure." Secara garis besar, langkah-langkah pokok dalam strategi konflik kognitif adalah: (1) identifikasi konsep salah yang dimiliki oleh siswa, (2) penciptaan kondisi konflik pada diri siswa melalui pemberian: fakta eksperimen, anomali, kontradiksi, (3) pemberian bantuan untuk terjadinya ekuilibrasi melalui: pertanyaan, pemberian informasi, rekonstruksi pemahaman siswa (Effendy, 2002).

Guru sebagai fasilitator dan mediator pembelajaran, pada saat munculnya miskonsepsi, sebaiknya menyajikan konflik kognitif sehingga terjadi ketidakseimbangan pada diri siswa. Konflik kognitif yang disajikan guru, diharapkan dapat menyadarkan siswa atas kekeliruan konsepsinya dan pada akhirnya mereka merekonstruksi konsepsinya menuju konsepsi ilmiah. Dengan demikian proses pembelajaran khususnya pembelajaran kimia akan menimbulkan suasana belajar yang bermakna (meaningful learning). Belajar bermakna terjadi bila informasi terkait dengan konsepkonsep relevan yang terdapat dalam struktur kognitif seseorang (Dahar, 1989).

Penelitian ini bertujuan untuk mengetahui efek penggunaan strategi konflik kognitif terhadap hasil belajar kognitif siswa. Hasil belajar dalam penelitian ini mengacu pada hasil belajar kognitif menurut Anderson dan Krathwol (2001), dimensi proses kognitif terbagi menjadi enam tingkatan, yaitu: mengingat (C1), memahami (C2), menerapkan (C3), menganalisis (C4), mengevaluasi (C5), dan menciptakan (C6).

\section{METODE PENELITIAN}

Penelitian ini merupakan penelitian eksperimen menggunakan one group pretest posttest design. Sampel penelitian adalah 35 orang siswa di salah satu sekolah menengah atas di Kota Mataram. Strategi konflik kognitif dikonduksikan pada pembelajaran fisika materi GLB dan GLBB. Data hasil belajar siswa dikumpulkan menggunakan 6 
butir test hasil belajar berbentuk essay dengan indikator C1-C6. Hasil analisis data hasil belajar kognitif siswa selanjutnya dikategorisasi menggunakan kategori hasil belajar kognitif seperti disajikan pada Tabel 1 berikut.

Tabel 1. Rentang nilai hasil belajar kognitif

\begin{tabular}{|c|c|c|}
\hline \multicolumn{2}{|c|}{ Rentang Nilai } & \multirow{2}{*}{$\frac{\text { Predikat }}{\mathrm{A}}$} \\
\hline 3.85 & $-4,00$ & \\
\hline 3.51 & $\begin{array}{l}-\quad 3.84 \\
\end{array}$ & A- \\
\hline 3.18 & $\begin{array}{l}-\quad 3.50 \\
\end{array}$ & $\mathrm{~B}+$ \\
\hline 2.85 & $\begin{array}{l}-\quad 3.17\end{array}$ & B \\
\hline 2.51 & $\begin{array}{l}-\quad 2.84 \\
\end{array}$ & B- \\
\hline 2.18 & $\begin{array}{l}-\quad 2.50 \\
-\end{array}$ & $\mathrm{C}+$ \\
\hline 1.85 & $\begin{array}{l}-\quad 2.17\end{array}$ & $\mathrm{C}$ \\
\hline 1.51 & $\begin{array}{l}-\quad 1.84 \\
\end{array}$ & $\mathrm{C}-$ \\
\hline 1.18 & $\begin{array}{l}-\quad 1.50 \\
\end{array}$ & $\mathrm{D}+$ \\
\hline 1.00 & $\begin{array}{l}-\quad 1.17\end{array}$ & $\mathrm{D}$ \\
\hline
\end{tabular}

Peningkatan hasil belajar kognitif siswa dianalisis secara statistik dengan bantuan SPSS for Windows 16 menggunakan analisis statistik parametrik dengan prasyarat data terdistribusi normal dan bervarian homogeny ( $\mathrm{p}>$ 0.05). Hasil analisis statistik juga diperkuat dengan skor n-gain hasil belajar kognitif siswa dan selanjutnya dikategorikan sesuai Tabel 2 (Hake, 1999).

Tabel 2. Kriteria perubahan skor (n-gain)

\begin{tabular}{cc}
\hline Rentang Skor & Keterangan \\
\hline$>0,70$ & Tinggi \\
$0,30-0,70$ & Sedang \\
$<0,30$ & Rendah \\
\hline
\end{tabular}

\section{HASIL DAN PENELITIAN}

Data hasil belajar kognitif siswa dikumpulkan menggunakan istrumen tes essay sebayak enam butir. Intrumen tes yang digunakan terlebih dahulu divalidasi secara isi maupun konstruk oleh 2 orang ahli sebelum digunakan mengumpulkan data hasil belajar kognitif siswa. Data hasil belajar siswa merupakan klasifikasi kognitif berdasarkan tingkat C1-C6. Data hasil belajar siswa dianalisis menggunakan uji Anova untuk menentukan distribusi data dan uji Levine untuk menentukan varian data. Hasil analisis distribusi dan varian data hasil belajar siswa disajikan pada Tabel 3 berikut.

Tabel 3. Distribusi dan Varian Data Hasil Belajar Kognitif Siswa

\begin{tabular}{|l|c|c|c|}
\hline $\begin{array}{l}\text { Kelompok } \\
\text { Data }\end{array}$ & \multirow{2}{*}{$\mathbf{N}$} & Normalitas & Homogenitas \\
\cline { 3 - 4 } & & Sig. & Sig. \\
\hline Pretest- & \multirow{2}{*}{35} & 0.556 & 0.662 \\
\hline Posttest & & & \\
\hline
\end{tabular}

Berdasarkan hasil analisis distribusi dan varian data hasil belajar siswa seperti disajikan pada Tabel 3 dapat diketahui data terdistribusi normal (0.556) dan bervarian homogeny (0.662) karena lebih besar dari alfa pengujian (0.05) sehingga dilakukan uji $\mathrm{t}$ berpasangan (paired sample $t$ test) untuk menentukan peningkatan skor hasil belajar kognitif siswa sebelum dan sesudah pembelajaran. Data hasil analisis peningkatan hasil belajar kognitif siswa disajikan pada Tabel 4 berikut.

Tabel 4. Peningkatan Hasil Belajar Kognitif Siswa

\begin{tabular}{|c|c|c|c|c|c|}
\hline Group & N & Skor & Mean & SD & p \\
\hline Pretest \& posttest & 35 & Pretest & 1.9600 & 0.48493 & 0.000 \\
\cline { 3 - 4 } & & Posttest & 3.4914 & & \\
\cline { 3 - 4 } & & n-gain & 0.74 & & \\
\hline \multirow{2}{*}{} & & & & \\
\end{tabular}

Tabel 4 menunjukkan bahwa hasil belajar kognitif siswa meningkat setelah pembelajaran menggunakan strategi konflik kognitif (mean: 3.4914) signifikan (p: 0.000). Hasil tersebut juga didukung hasil analisis ngain hasil belajar kognitif siswa setelah pembelajaran dengan nilai 0.74 dengan kategori tinggi sehingga dinyatakan efektif untuk meningkatkan hasil belajar kognitif siswa. Peningkatan hasil belajar kogntif siswa tersebut sejalan dengan pernyataan Chandrasegaran (2009) bahwa pembelajaran dengan menggunakan strategi konflik kognitif menuntut siswa mengkonstruksi 
pengetahuannya sendiri. Siswa melalui proses asimilasi dan akomodasi. Dalam proses asimilasi, informasi baru yang diperoleh siswa dicocokkan dengan konsep yang sudah ada dalam pikirannya. Apabila informasi baru tersebut tidak sesuai dengan konsep yang ada dalam pikirannya, maka siswa akan mengubah konsep dalam pikirannya terebut melalui proses akomodasi sehingga menguatkan pemahaman konsep dan meningkatkan hasil belajar siswa.

Strategi konflik kognitif merupakan strategi pengubah konsepsi (conceptual change strategies) yang berdasarkan pada pandangan konstruktivisme, yaitu suatu strategi pembelajaran bagaimana membuat pikiran siswa agar menyadari kekeliruan konsepsinya, sehingga melalui proses akomodasi diharapkan dapat berubah menjadi konsepsi ilmiah. Dalam banyak penelitian diungkapkan bahwa teori perubahan konsep dipengaruhi oleh filsafat konstuktivisme. Untuk menimbulkan konflik kognitif pada siswa, dapat dilakukan dengan penyajian contoh-contoh tandingan, analogi, demonstrasi, dan eksperimen (Dreyfus, 1990).

Secara garis besar, langkah-langkah pokok dalam strategi konflik kognitif adalah terdiri dari 4 fase yaitu identifikasi miskonsepsi, penciptaan kondisi konflik, pemberian bantuan agar terjadi ekuilibrasi, dan rekonstruksi pemahaman siswa. Pada fase pertama menunjukkan selama pembelajaran siswa cenderung mengalami miskonsepsi pada konsep-konsep perpindahan, jarak, dan kecepatan sesaat ditinjau pada perubahan waktu. Fenomena tersebut harus diperbaiki agar pembelajaran dapat berjalan efektif. Sejalan dengan pernyataan dan hasil temuan tersebut, Nur (1999) menyatakan bahwa pengetahuan awal siswa dapat membantu mengarahkan konsep yang dimiliki siswa menuju konsep yang benar. Langkah yang perlu dilakukan dalam pembeljaran adalah memberikan situasi konflik (fase dua). Tujuan guru memberikan situasi konflik ini agar siswa menyadari bahwa konsep yang dimilikinya salah dengan memberikan contoh-contoh tandingan (Chinn, 1993). Pada fase ini, guru tidak langsung menyalahkan prakonsepsi siswa dan memaksa siswa untuk menerima konsep baru yang diajarkan, melainkan siswa diarahkan untuk mengubah sendiri prakonsepsi siswa yang salah. Menurut teori bermakna Ausubel, belajar bermakna terjadi apabila ada suatu proses yang mengaitkan informasi baru pada konsep yang relevan yang telah ada pada struktur kognitif seseorang (Nur, 1999). Fase ketiga adalah pemberian bantuan agar terjadi ekuilibrasi. Pemberian bantuan agar terjadi ekuilibrasi pada siswa, menurut teori Piaget yang menyatakan bahwa perubahan kognitif dan belajar akan berlangsung apabila skema mengalami gangguan. Gangguan ini akan menyebabkan terjadinya akomodasi yang mengarah pada terciptanya kesetimbangan baru. Pemberian bantuan untuk terjadinya proses ekuilibrasi ini dapat melalui pertanyaan atau pemberian informasi (Effendy, 2005). Pada fase akhir dari strategi konflik kognitif adalah merekonstruksi pemahaman siswa untuk memperkuat pemahaman siswa terhadap konsep, sehingga miskonsepsi yang dialami sebelumnya telah hilang dan beralih menjadi konsep benar yang dapat tertanam dengan kuat. Proses-proses seperti diuraikan tersebut dilakukan selama pembelajaran sehingga hasil belajar kognitif siswa mengalami peningkatan yang baik menggunakan strategi konflik kognitif.

Selain melaui penyajian-penyajian fenomena konflik kognitif, interaksi siswa dengan lingkungan juga ditekankan selama pembelajaran sehingga membatu siswa lebih memahami materi yang dibelajarkan. Piaget (Hughes, 2012) menemukan bahwa perkembangan kognitif sebagian besar 
bergantung pada seberapa jauh anak akan aktif berinteraksi dengan lingkungannya. Di dalam kelas, penyajian pengetahuan dengan mendorong siswa menemukan sendiri pengetahuan tersebut dilakukan melalui interaksi dengan lingkungan maupun dengan bahan ajar.

\section{KESIMPULAN}

Berdasarkan hasil penelitian dapat dinyatakan bahwa penggunaan strategi konflik kognitif berefek secara signifikan pada peningkatan hasil belajar kognitif siswa pada materi pokok GLB dan GLBB dengan ngain berkategori tinggi. Hambatan-hambatan yang ditemukan dalam penelitain adalah kesulitan siswa dalam memahami konsep perpindahan, jarak, dan percepatan sesaat, sehingga dalam pembelajaran penting untuk menyediakan fenomena-fenomena autentik terkait materi-materi yang akan dibelajarkan untuk mengidentifikasi kesulitan konsep siswa secara konprehensif agar perlakuan dalam pembelajaran lebih tepat.

\section{DAFTAR PUSTAKA}

Anderson, L.W. \& Krathwohl, D.R. 2001. A Revision of Bloom's Taxonomy of Educational Objectives. New York: Addison Wesley Longman, Inc.

Arikunto, S. 1995. Dasar-Dasar Evaluasi Pendidikan. Bumi Aksara: Yogyakarta

Chandrasegaran, A.L., Treagust, D.F., \& Waldrip, B.G. 2009. "Students' Dilemmas in Reaction Stoichiometry Problem Solving: Deducing the Limiting Reagent in Chemical Reaction". Chemistry Education Research and Practice, (10): 14-23.

Chinn, C.A. 1993. "The Role of Anomalous Data in Theory Change: A Cognitive Analysis". The Proceedings of the Third International Seminar on
Misconception and Educational Strategy in Science and Mathematics. Ithaca.

Dahar, R.W. 1989. Teori-Teori Belajar. Jakarta: P2LPTK.

Dreyfus. 1990. "Educational Experience and Cognitive Development". Educational Psychologist Journal. 12 (2):179-197.

Effendy. 2002. Upaya untuk Mengatasi Kesalahan Konsep dalam Pengajaran dengan Menggunakan Strategi Konflik Kognitif. Media Komunikasi Kimia, 2 (6): 1-19.

Ernest, P. 1991. The Philosophy of Mathematics Education. London: Routledge Falmer

Foster, C. (2011). A slippery slope: Resolving cognitive conflict in mechanics. Teaching Mathematics and Its Applications, 30, 216-221.

Hake. (1999). Analyzing Change/Gain Scores.

http://www.physics.indiana.edu/sdi/Ana lyzingChange-Gain.pdf.

Hewson, D. W., \& Hewson, M. G. (1984). The Role of conceptual conflict in conceptual change and the design of science instruction. Instructional Science, 13, 1-13.

Hughes, A.G. dan E.G. Hughes, 2012. Learning and Teaching: Pengantar Psikologi Pembelajaran Modern, Penerbit Nuansa, Bandung.

Kang, S., Scharmann, L.C., and Noh, T. (2004). Reexamining the role of cognitive conflict in science concept learning. Research in Science Education, 34, 71-96.

Kwon, j \& lee, g. 2001. "What do you know about students cognitive conflict: a theoritical model of cognitive conflict process". Proseeding of 2001 AETS annual meeting, costa mesa, CA, pp. 309-325 
Lee, G., Kwon, J., Park, S., Kim, J., Kwon, H., \& Park, H. (2003). Development of an instrument for measuring cognitive conflict in secondary-level science classes. Journal of Research in Science Teaching, 40 (6), 585-603.

Nur, M. 1999. Teori Belajar. Surabaya: UNESA University Press

Slavin, R.E. 1997. Educational Psychology Theory and Practice. Fourth Edition. Massachusetts: Allyn and Bacon Publishers.

Sudjana, N. (2010). Penilaian Hasil Proses Belajar Mengajar. Bandung: PT Remaja Rosdakarya. 